\section{耍 Heighten Science \\ P U B L I C I T I O N S Corporation ISSN 2573-1726}

\title{
Retrospective Analysis of Non- Contact ACL Injury Risk: A Case Series Review of Elite Female Athletes
}

\author{
Lee Herrington ${ }^{1 *}$ and Ros Cooke \\ ${ }^{1}$ Senior Lecturer in Sports Rehabilitation, Directorate of Sport, University of Salford, UK \\ ${ }^{2}$ Lead Physiotherapist, England Netball and English Institute of Sport, UK
}

\begin{abstract}
*Address for Correspondence: Lee Herrington, PhD MCSP, Senior Lecturer in Sports Rehabilitation, Directorate of Sport, University of Salford, UK, Email: I.c.herrington@salford.ac.uk

Submitted: 30 December 2016

Approved: 03 February 2017

Published: 06 February 2017
\end{abstract}

Copyright: $\circledast 2017$ Herrington L, et al. This is an open access article distributed under the Creative Commons Attribution License, which permits unrestricted use, distribution, and reproduction in any medium, provided the original work is properly cited.

Keywords: ACL; Risk factors; Female

\section{ABSTRACT}

Background: Literature on ACL injury is limited when assessing for the presence and interaction of multiple risk factors simultaneously. Identifying risk factor interaction may increase the impact of prevention programmes to target $\mathrm{ACL}$ injury reduction. The aim of this study was to retrospectively assess $A C L$ injured female athletes to identify which modifiable and non-modifiable risk factors were present at the time of injury.

Method: Seventeen female athletes who had sustained a non-contact ACL injury were interviewed retrospectively to assess for the presence of reported risk factors for $A C L$ injury.

Result: This retrospective analysis $A C L$ injury cases highlighted a number of factors which were present with high frequency across this group of cases. All had non-contact ACL injury occurring during cutting or landing, which suggests a predisposing deficit in neuromuscular control. This poor neuromuscular control could be exacerbated by the presence of fatigue identified within the cohort. This poor control could be further influenced by the fact a majority of athletes had another significant injury in the 12 weeks prior to ACL injury. The restriction to training could have either decreased fatigue resistance, or potentially changed their movement pattern because of the method of injury management undertaken.

Conclusion: This case series provides insight into the interaction of risk factors for ACL injury in sportswomen, with the presence of another injury disrupting training, decreasing the athletes work capacity and fatigue resistance, being compounded perceived or actually elevated levels of fatigue, leading to the potential for abhorrent movement patterns and increased injury risk.

\section{INTRODUCTION}

Anterior cruciate ligament (ACL) injuries continue to be one of the most debilitating injuries, in terms of the time lost from sport participation [1], the significant ongoing comorbidities which can be developed [2] and the heighten risk of further ACL injury [3]. Approximately 70\% of ACL tears occur from a noncontact mechanism [4] with the research literature identifying both modifiable and non-modifiable risk factors predisposing the individual to increased risk of non-contact ACL injury [5,6]. Identifying the presence and significance of non-modifiable risk factors may increase the impact of prevention programmes which aim the target the modifiable risk factors or allow other interventions to be undertaken to try and mitigate risk. Currently literature is limited on assessing for the presence and interaction of multiple risk factors simultaneously $[5,6]$.

The classification of risk factors into modifiable and non-modifiable may be expanded upon further by considering if the individual risk factor as either an extrinsic 
or intrinsic one. Intrinsic variables include those inherent to the individual athlete, such as sex, hormonal milieu, genetic factors, neuromuscular and cognitive function, anatomic variables (e.g., knee joint geometry, lower extremity alignment, body mass index), and previous injury to the knee or the lower extremity. Extrinsic factors are external to the athlete and may include level and type of activity, type of playing surface and environmental conditions, as well as equipment used. Listing risk factors in this manner may allow the practitioner to start to be able to prioritise factors which can be modified for the individual to reduce overall risk of injury.

A number of studies have looked at manipulating neuromuscular control with training in order to mitigate the risk of ACL injury, as this would appear to be the most obvious factor to change; these studies have met with some notable successes [1]. These programmes may prove even more effective if they are targeted at those of highest risk, as it would appear that risk factors interact to increase likelihood of injury [5]. Those at heightened risk would appear to be female athletes, those with previous ACL injury, family history of ACL history and have generalised laxity [5,6].

Alongside these factors others also appear to have the potential to have a significant impact on injury risk. For example, prior injury to the hamstring muscles [7] or patellofemoral joint [8] have both been speculated to predispose the individual to ACL injury. This relationship might be due to the detraining effect of the previous injury or the prior injury itself might more directly impact on the neuromuscular control of the limb, directly through changes in movement patterns as a result of the injury or indirectly as a result of muscle inhibition and weakness created. It may though in fact be difficult truly ascertain if it is the injury itself which predisposes to an ACL or the common risk factors between problems such as patellofemoral joint pain and ACL injury [8].

Fatigue has been shown to significantly impact on neuromuscular performance especially females [9], though the impact of fatigue through increased competition or training loads on ACL injury rates appears not to have been considered in the literature. Being in competition as opposed to training is another factor which heightens risk [10]; again here this might be to the intensity of the physical activity and/or the accumulation of fatigue because of either the intensity of performance or having to perform on multiple occasions in a short space of time as with tournament play.

Cognitive stress-fatigue is a relatively under researched area in relation to predisposing athletes to injury. It is know that disturbance to normal sleep patterns can affect performance [10] this disturbance to sleep could be from changes in circadian rhythm, due to changing time zones, long haul travel, or from cognitive stress. Cognitive stress, expressed through sleep disturbance, anxiety and depression has been associated with significant musculoskeletal injuries in professional footballers [11], though this has not been investigated specifically for ACL injury or in female athletes.

The aim of this study was to assess retrospectively previously ACL injured elite female athletes to identify which potential extrinsic and intrinsic modifiable and nonmodifiable risk factors for ACL injury, were present at the time of injury and were common across the group. Then from this information attempt to identify specific factors or behaviours which may place an individual at higher risk.

\section{METHOD}

\section{Participants}

Seventeen female athletes ( $20 \pm 4.8$ years) who all sustained a non-contact ACL injury were recruited. The injury was diagnosed from MRI and orthopaedic surgeon assessment. The injuries all occurred during competitive play, involving either 
landing onto the leg or cutting on the leg which was injured. All subjects were national-international level full time athletes from the following sports: Soccer $(n=4)$; Taekwondo $(n=4)$; Netball $(n=9)$. The participants were initially selected from the medical records database of the English Institute of Sport if they had a diagnosis of ACL rupture, subjects were then excluded if the injury was not managed surgically and if the injury had not occurred in competition. By taking athletes injured in competition only this allows some control over the environmental factors such as training-competition load, playing surface, travel stress and general levels of competitive stress levels. The group of athletes then left were approached to see if they wished to participate in the study. The study had approval by University research ethics committee and all participating athletes gave written consent.

\section{Procedures}

Information was either collected directly from a semi-structured interview of the athlete or from their medical records in order to answer the questions found in table 1.

\section{RESULTS}

Table 2 displays the full results of the retrospective audit. Fourteen out of the 17 athletes audited (82\%) had a score of 4 or higher on the Beighton hypermobility scale. A similar number had genu recurvatum present prior to ACL rupture. Eight out of the $17(47 \%)$ had history of previous ACL rupture of the same or other limb. Five out of the 17 (29\%) had familial history of ACL rupture (sibling or parental). Thirteen out of the $17(77 \%)$ had had an injury which disrupted and restricted training in the 12 weeks prior to rupturing the ACL (Table 3). Fourteen out of the 17 athletes audited (82\%) had a fatiguing event either physical or cognitive at some point in the 7 days prior to rupturing their ACL (Table 4).

\section{DISCUSSION}

It has been previously reported that generalised laxity, previous ACL injury and family history of ACL injury all heighten the risk of sustaining an ACL injury [5,6], the findings of this retrospective audit of injured athletes support this previous work.

Table 1: Information extracted by the audit

\begin{tabular}{|c|c|c|}
\hline Information sort & Source & Question asked at interview \\
\hline Beighton Hypermobility Score ${ }^{1}$ & $\begin{array}{l}\text { Subjects medical } \\
\text { records }\end{array}$ & Not applicable \\
\hline Significant Genu Recurvatum² & $\begin{array}{l}\text { Subjects medical } \\
\text { records }\end{array}$ & Not applicable \\
\hline Previous ACL injury & $\begin{array}{l}\text { Subjects medical } \\
\text { records \& athlete } \\
\text { interview }\end{array}$ & Have you previously damaged your ACL in either leg? \\
\hline Family history ACL injury & Athlete interview & $\begin{array}{l}\text { Has anyone in your direct family (siblings or parents) } \\
\text { ever damaged their ACL? }\end{array}$ \\
\hline $\begin{array}{l}\text { Other injury }{ }^{3} \text { within } 12 \text { weeks } \\
\text { of } A C L \text { injury }\end{array}$ & $\begin{array}{l}\text { Subjects medical } \\
\text { records \& athlete } \\
\text { interview }\end{array}$ & $\begin{array}{l}\text { Have you had any lower limb injury which disrupted } \\
\text { your training or restricted your ability training in the } \\
\text { last } 3 \text { months? }\end{array}$ \\
\hline $\begin{array}{l}\text { Physical or cognitive fatiguing } \\
\text { event in week prior injury }\end{array}$ & Athlete interview & $\begin{array}{l}\text { In the week prior to your } A C L \text { injury did any of the } \\
\text { following happen: } \\
\text { - Long haul flight } \\
\text { - Significant increase in training load } \\
\text { - Participate in a multi-match tournament } \\
\text { - Change time zones } \\
\text { - Significant (greater than } 2 \text { nights) disruption to sleep } \\
\text { - Increase cognitive stress }{ }^{4}\end{array}$ \\
\hline \multicolumn{3}{|c|}{$\begin{array}{l}\left.{ }^{1} \text { Assess using the rating scale reported ( } 27\right) \\
\left.{ }^{2} \text { Greater than } 10 \text { degrees of knee hyperextension ( } 28\right) \\
{ }^{3} \text { An injury when caused greater than two days missed training or competition ( } 29 \text { ) } \\
{ }^{4} \text { Increased cognitive stresses included; relationship issues, performance issues (identified by coach or perceived } \\
\text { by player), abnormally high performance anxiety }\end{array}$} \\
\hline
\end{tabular}


Table 2: Summary of athlete reported risk factors.

\begin{tabular}{|c|c|c|c|c|c|c|c|c|c|c|c|c|c|c|c|c|c|}
\hline \multirow{2}{*}{$\begin{array}{l}\text { Risk Factor } \\
\text { Beighton Score }\end{array}$} & \multicolumn{17}{|c|}{ Athlete } \\
\hline & 8 & 8 & 8 & 6 & 5 & 4 & 4 & 4 & 4 & 5 & 9 & 0 & 4 & 4 & 0 & 0 & 5 \\
\hline Genu Recurvatum & yes & yes & yes & yes & yes & yes & yes & yes & yes & yes & yes & No & yes & yes & no & no & yes \\
\hline Previous ACL injury* & no & yes & yes & no & yes & no & no & yes & yes & no & yes & yes & yes & no & no & no & no \\
\hline Family history ACL injury & no & no & no & yes & no & no & no & no & yes & no & yes & no & no & no & no & yes & yes \\
\hline Injury within last three months & yes & yes & yes & yes & yes & yes & yes & no & no & yes & yes & no & yes & no & yes & yes & yes \\
\hline $\begin{array}{l}\text { Fatigue event in week prior injury (training, long haul } \\
\text { flight, time zone, cognitive stress) }\end{array}$ & yes & yes & yes & yes & yes & yes & yes & yes & no & yes & yes & yes & yes & no & yes & yes & no \\
\hline Sport & Tkd & Tkd & NB & NB & Tkd & FB & FB & FB & FB & Tkd & NB & NB & NB & NB & NB & NB & NB \\
\hline
\end{tabular}

Key: Tkd Taekwondo NB netball FB football (soccer)

*Previous ACL 7 of the 8 were contralateral one was ipsilateral

Table 3: Injuries in the preceding twelve weeks to ACL injury.

\begin{tabular}{|l|l|}
\hline Injury & \multicolumn{1}{|c|}{ Number of athletes $(n=13)$} \\
\hline Grade 1 or $\mathbf{2}$ disruption anterior talofibular ligament at the ankle & 8 \\
\hline Patellofemoral joint pain & 2 \\
\hline Hamstring muscle injury (grade 1) & 1 \\
\hline Gastrocnemius muscle injury (grade 1) & 1 \\
\hline Patella Tendinopathy & 1 \\
\hline
\end{tabular}

Table 4: Factors creating fatigue in seven days prior to ACL injury.

Factor creating fatigue

Number of athletes $(n=14)$

Long haul flight in preceding 7 days

$18 \%$ (3 out of 17 )

Participation in multiple competition matches in preceding 7 days

$77 \%$ (13 out of 17 )

Disturbed sleep (greater than 2 nights) in preceding 7 days

$65 \%$ (11 out of 17 )

Significant increase in acute training load in preceding 7 days

$77 \%$ (13 out of 17 )

Performance anxiety

$29 \%$ (5 out of 17 )

Performance issues

$35 \%$ ( 6 out of 17 )

Relationship issues

$12 \%$ (2 out of 17 )

Note athletes have reported more than one factor occurring simultaneously

Significant numbers of these female athletes had positive findings for these injury risk characteristics. Though the numbers with previous contralateral or ipsilateral ACL injury are greater than those previously reported for an athletic female population [3], these findings do fit with the contention that the greater the level of sporting activity the patient returns to the greater the risk of further injury [12]. A genetic or familial relationship has been proposed in the aetiology of ACL [6] this study would support that contention of a potential link.

This to our knowledge is the first study to report on the potential association between perceived physical or cognitive fatigue and ACL injury, the relationships found, are an interesting finding which would appear to be worthy of further and far more detailed study than the open ended questions used in the present study. This injury audit found 14 out of the 17 athletes audited (82\%) had a fatiguing event, either physical or cognitive at some point in the 7 days prior to rupturing their ACL (Table 4). The fatiguing events inquired after in this study were: physical, such as a significant increase in training load or the participation in a multi-event competition; environmental, here athletes were questioned if they had changed time zones and undertaken long haul travel along with any consistent (greater than two nights) disturbance of sleep; and finally questioning related to cognitive stress (load) which included issues related to relationship issues, performance issues (identified by coach or perceived by player) and abnormally high performance anxiety. Saw et al. [13] found 
in their systematic review that athlete reported subjective information was highly sensitive to changes in athlete workload and physiological and psychological stress, so it is likely that these findings have some validity in demonstrating the athletes loading environment. Increases in acute training loads have been reported to significantly impact on the rate of injury [14]. This study has indicated that not on physical but cognitive loads should possibly be accounted for when assessing acute loading stress on the athlete.

The relationship of fatigue to ACL injury is a speculative one; it is based on the hypothesis that fatigue will impair the athlete's ability to move optimally, and therefore be more likely to adopt movement strategies associated with the increase the risk of injury $[9,15]$. There are a number of studies which have shown fatigue to create suboptimal movement patterns which have been associated with ACL injury $[9,15]$. There is some supporting evidence of how fatigue may increase the risk of injury. Studies have shown that muscle fatigue reduces the neuromuscular systems adaptability to external perturbations [16], so the athlete may be less able to react to altered loading when landing or changing direction during a game. The neuromuscular and perceptual fatigue created by consecutive days of tournament play can create impairments in sprinting and jumping ability, and biochemical markers of muscle damage and reduced mood states [17], all of which may reduce the athlete's ability to move and land optimally. Similarly, in relation to more cognitive factors, mental fatigue has been shown to impair intermittent running performance [18], with depressive symptoms and daytime sleepiness positively associated with musculoskeletal injury [19]. Furthermore, sleep disturbance was found to be significantly related to work related injuries by Uehli et al. [20].

Thirteen out of the 17 (77\%) had had an injury which disrupted and restricted training in the 12 weeks prior to rupturing the ACL (Table 3). A consistent finding within the literature is that history of previous injury appears to predict future injury [21]. Furthermore, prior injury to the hamstring muscles [7] or patellofemoral joint [8] have both been speculated to predispose the individual to ACL injury. This relationship may be related to lost training time reducing the capacity to perform at high intensity for prolonged periods, the lack of fatigue resistance leading to a greater propensity to develop abnormal and potentially injurious movement patterns [15]. Interestingly, the most common injury sustained in this group was a lateral ligament injury of the ankle (8 of the 13) (Table 3), there might be a number of reasons why this type of injury could predispose the athlete to an ACL injury. Bullock-Saxton [22] reported significant decreases in gluteal muscle EMG activity following ankle ligament injury, gluteal muscle activity would appear critical in controlling the valgus collapse of the knee [23] which has been linked to ACL injury [1]. Evidence exists that postural control and balance are altered after ankle ligament injury [24] this again could lead to abnormal and potential injurious movement patterns. A final potential reason why ankle ligament injury could create movement patterns which could predispose the athlete to ACL injury is the typical way these injuries are managed. First line treatment for ankle ligament injuries is often to use tape to restrict movement to protect the damaged ligaments [25]. Limitation of ankle dorsi-flexion range of movement has been shown to be linked to increased knee valgus during a variety of functional tasks [26] which could predispose the individual to ACL injury.

This retrospective analysis of a series of ACL injury cases highlighted a number of potentially modifiable factors which were present with relatively high frequency across this group of cases. The athletes within this group all had a non-contact ACL injury occurring during cutting or landing, which suggests a predisposing deficit in neuromuscular control. This poor neuromuscular control could be exacerbated by the presence of fatigue identified within the cohort. The poor control could be further influenced by previous injury either decreasing work capacity and fatigue resistance or 
changing movement pattern because of the method of injury management undertaken. The findings of this study might have an impact on those working to prevent ACL injury, especially in elite sport. It would appear that risk could be heightened if the non-modifiable factors such as hypermobility and family history occur in an athlete who also has poor neuromuscular control; this has already been identified to a degree in the literature [5]. This study has added to this combination of factors, identifying that likelihood of injury could possibly be increased further if the athlete has an injury which restricts training in the period prior to the ACL injury, with ankle ligament injury seeming to be significant amongst these. The presence of another injury might disrupt training, decreasing the athletes work capacity and fatigue resistance, if the athlete then has perceived or an actual elevated level of fatigue, this may compound the situation further, with the greater the levels of fatigue the greater the potential for abhorrent movement patterns and injury risk. When returning an athlete following an injury which has disrupted training, consideration should be given not only to them being asymptomatic and being able to pass appropriate fitness tests, but also that they have recovered their chronic training capacity, so they are able to cope with acute increases in load better [14].

The study lacks a control group to compare the factors found in the injured group too; this could be regarded as a potential weakness in the study. What must be taken into account here is that these athletes were all national-international athletes participating in very structured training and competitive programme; so many elements are common to all participating athletes. It is likely that what is being seen in the athletes who get injured is a multiplier effect were a number of factors interact. The assessment and understanding of how these interactions create injury is beyond the scope of this case series and certainly requires further prospective study. What is apparent from this case series is ACL injury is unlikely to be related to a single factor, but a critical tipping factor might be loss of chronic training capacity or a perceived or actual increase in acute physical load [14].

This case series has shown that a number of previously reported factors potentially interact to create ACL injury. The risk might be elevated if the athlete lacks chronic training capacity, in these cases through either injury in the period prior to the ACL injury and then an increased acute load [14]. Those working with female elite athletes should consider the level of chronic load the tissues and athlete has been exposed in comparison to the acute load requirements of return to competition, attempting to minimise the mis-match to minimise injury risk. In a similar vein, those working with these athletes should attempt to minimise large increases in acute load real or perceived to also reduce the risk of injury.

\section{REFERENCES}

1. Hewett T, Di Stasi S, Myer G. Current concepts for injury prevention in athletes after anterior cruciate ligament reconstruction. Am J Sports Med. 2013; 41:216-224. Ref.: https://goo.gl/slhO5s

2. Culvenor AG, Collins NJ , Guermazi A, Cook J L, Vicenzino B, et al. Early osteoarthritis is evident one year following anterior cruciate ligament reconstruction. Arth Rheumatol. 2015; 67: 946-955. Ref.: https://goo.gl/Xnylw5

3. Paterno MV, Rauh MJ , Schmitt LC, Ford KR, Hewett TE. Incidence of second ACL injuries 2 years after primary ACL reconstruction and return to sport. Am J Sports Med. 2014; 42: 1567-1573. Ref.: https://goo.gl/ppRAkP

4. Postma WF, West RV. Anterior cruciate ligament injury prevention programs. J Bone J t Surg. 2013; 95: 661-665. Ref.: https://goo.gl/cNSdpl

5. Smith H, Vacek P, J ohnson R, Slauterbeck J, Hashemi J, et al. Risk factors for anterior cruciate ligament injury: a review of the literature - part 1:neuromuscular and anatomic risk. Sports Health. 2012; 4: 69-78. Ref.: https://goo.gl/lu6zeV

6. Smith H, Vacek P, J ohnson R, Slauterbeck J, Hashemi J, et al. Risk factors for anterior cruciate 
ligament injury: a review of the literature - part 2: hormonal, genetic, cognitive function, previous injury and extrinsic risk factors. Sports Health. 2012; 4: 155-161. Ref.: https://goo.gl/ZD2IPC

7. Opar D, Serpell B. Is there a potential relationship between prior hamstring strain injury and increased risk for future anterior cruciate ligament injury. Arch Phys Med Rehab. 2014; 95: 401-405. Ref.: https://goo.gl/kFyLxE

8. Myer G, Ford K, Di Stasi S, Foss K, Micheli L, et al. High knee abduction moment are common risk factors for patellofemoral pain (PFP) and anterior cruciate ligament (ACL) injury in girls: is PFP itself a predictor for subsequent ACL injury? Brit J Sports Med. 2015; 49: 118-122. Ref.: https://goo.gl/xcy6nO

9. Wesley C, Aronson P, Docherty C. Lower extremity landing biomechanics in both sexes after a functional exercise protocol. J Athl Train. 2015; 50: 914-920. Ref.: https://goo.gl/px1xgu

10.J oseph A, Collins C, Henke N, Yard E, Fields S, et al. A multisport epidemiologic comparison of anterior cruciate ligament injuries in high school athletics. J Athl Train. 2013; 48: 810-817. Ref.: https://goo.gl/T3PBfH

11.Gouttebarge V, Aoki H, Ekstrand J, Verhagen E, Kerkhoffs G. Are severe musculoskeletal injuries associated with symptoms of common mental disorders among European professional footballers? Kn Surg Sports Traum Arthros 2015. 24: 3934-3942. Ref.: https://goo.gl/sA3rPi

12.Sousa P, Krych A, Cates R, Levy B, Stuart M, et al. Return to sport: Does excellent 6 month strength and function following $A C L$ reconstruction predict midterm outcomes. Kn Surg Sports Traum Arthros. 2015; [Epub ahead of print]. Ref.: https://goo.gl/0eDV8Y

13.Saw A, Main L, Gastin P. Monitoring the athlete training response: subjective self-reported measures trump objective measures: a systematic review. Brit J Sports Med. 2015; 50: 281-291. Ref.: https://goo.gl/XAOWls

14. Hulin B, Gabbett T, Lawson D, Caputi P, Sampson J . The acute:chronic workload ratio predicts injury: high chronic workload may decrease injury risk in elite rugby league players. Brit J Sports Med. 2016; 50: 231-236. Ref.: https://goo.gl/vMNonS

15. Herrington L. Effect of hip abductor muscle fatigue on knee valgus angle during a unilateral step landing task. Int J Athl Ther Train. 2013; 19: 38-43.

16.Pethick J , Winter S, Burnley M. Fatigue reduces the complexity of knee extensor torque fluctuations during maximal and submaximal intermittent isometric contractions. J Physiol. 2015; in press DOI: 10.1113/jphysiol.2014.284380. Ref.: https://goo.gl/yNIVN4

17.Gescheit D, Cormack S, Reid M, Duffield R. Consecutive Days of Prolonged Tennis Matchplay: Performance, Physical, and Perceptual Responses in Trained Players Int J Sports Physiol Perform. 2015; 10: 913-920. Ref.: https://goo.gl/0g7pNa

18.Smith $M$, Samuelle $M$, Coutts $A$. Mental fatigue impairs intermittent running performance. Med Sci Sport Exs. 2015; 47: 1682-1690. Ref.: https://goo.gl/2LaO4G

19.Sandberg J , Grzywacz J ,Talton J , Quandt S, Chen H, et al. A cross sectional exploration of excessive daytime sleepiness, depression and musculoskeletal pain among migrate farmworkers. J Agromed. 2012; 1: 70-80. Ref.: https://goo.gl/Pvv5Ze

20.Uelhi K, Miedinger D, Bingisser R, Durr S, Holsboer-Tachsler E, et al. Sleep problems and work injury types: a study of 180 patients in a Swiss emergency department. Swiss Med Week. 2013; 143: w13902. Ref.: https://goo.gl/4UHLS7

21.Garrison $M$, Westrick $R$, J ohnson $M$, Benenson I. Association between the functional movement screen and injury development in college athletes. Int J Sports Phys Ther. 2015; 10: 21-28. Ref.: https://goo.gl/PYbKlo

22.Bullock-Saxton J . Local sensation changes and altered hip muscle function following severe ankle sprain. Phys Ther 1994; 74: 17-28. Ref.: https://goo.gl/yiQAgu

23. Homan K, Norcross M, Goerger B, Prentice W, Blackburn T. The influence of hip strength on gluteal activity and lower extremity kinematics. J Electromyo Kinesio. 2013; 23: 411-415. Ref.: https://goo.gl/1U306u

24.McKeon P, Hertel J. Systematic review of postural control and lateral ankle instability, part 1: can deficits be detected with instrumented testing. J Athl Train. 2008; 43: 293-304. Ref.: https://goo.gl/qy56fH

25.Van den Bekerom M, van Kimmenade R, Sierevelt I, Eqqink K, Kerkhoffs G, et al. Randomised comparison of tape versus semi-rigid and versus lace-up ankle support in the treatment of 
acute lateral ankle ligament injury. Kn Surg Sports Trauma Arthros. 2015; 24: 978-984. Ref.: https://goo.gl/63xwEF

26. Rabin A, Kozol Z. Measures of range of motion and strength among healthy women with differing quality of lower extremity movement during the lateral step down tests. J Orthop Sports Phys Ther. 2010; 40: 792-800. Ref.: https://goo.gl/HmEouZ

27.Smits-Engelsman B, Klerks M, Kirby A. Beighton score: a valid measure for generalisied hypermobility in children. J ournal of Pediatrics. 2010; 158: 119-123. Ref.: https://goo.gl/YP2snh

28.Saito K, Hatayama K, Terauchi M, Haqiwara K, Hiquchi H, et al. Clinical outcomes after anatomic double-bundle anterior cruciate ligament reconstruction: comparison of extreme knee hyperextension and normal to mild knee hyperextension. Arthros. 2015; 31: 1310-1317. Ref.: https://goo.gl/X8rz5D

29.Brimitt J , Heiderscheit B, Manske R, Niemuth P, Rauh M. Lower extremity functional tests and risk of injury in division III collegiate athletes. Int J Sports Phys Ther. 2013; 8: 216-227. Ref.: https://goo.gl/xZ5MOP

30.Fullagar H, Skorski S, Duffield R, Hammes D, Coutts A, et al. Sleep and athletic performance: The effects of sleep loss on exercise performance and physiological and cognitive responses to exercise. Sports Med. 2015; 45: 161-186. Ref.: https://goo.gl/d6J wah 